\title{
INFLUENCE OF TOBACCO USE IN DENTAL CARIES DEVELOPMENT
}

\author{
Sajith Vellappally ${ }^{1}, Z_{\text {Zdeněk Fiala }}{ }^{1}$, Jindra Šmejkalová ${ }^{1}$, Vimal Jacob ${ }^{1}$, Pilathadka Shriharsha ${ }^{2}$ \\ ${ }^{1}$ Department of Hygiene and Preventive Medicine, Charles University in Prague, Faculty of Medicine in Hradec Králové, Czech Republic \\ ${ }^{2}$ Department of Dentistry, Charles University in Prague, Faculty of Medicine in Hradec Kralové, Czech Republic
}

\section{SUMMARY}

This review article describes different forms of tobacco usage and its direct relationship with the prevalence of dental caries. Smoking along with co-existing factors like old age, bad oral hygiene habits, food habits, limited preventive dental visits and over all health standards, can be associated with high caries incidence. However, a direct etiological relationship is lacking. Environmental tobacco smoke (ETS) causes dental caries in children but no studies have been reported in adults. Existing findings are not sufficient and conclusive enough to confirm that ETS causes dental caries. Oral use of smokeless tobacco (ST), predominantly tobacco chewing, is presumably a positive contributing factor to higher incidence of dental caries. Unfortunately, published studies are not converging towards one single factor through which tobacco usage can have direct relationship to dental caries.

Key words: dental caries, tobacco smoking, environmental tobacco smoke, smokeless tobacco

Address for correspondence: S. Vellappally, Faculty of Medicine, Department of Hygiene and Preventive Medicine, Šimkova 870, 50038 Hradec Králové, Czech Republic. E-mail: drvellappally@rediffmail.com

\section{INTRODUCTION}

Cigarette smoking and other tobacco use imposes a huge and growing burden for public health globally. Approximately 5 million people are killed annually by tobacco use. By the year 2030, according to current trends, it is assumed that this number will increase to 10 million with $70 \%$ of deaths occurring in low and middle income countries. Numerous studies from high-income countries, and a growing number from low and middle income countries, provide strong evidence that tobacco taxes increase, dissemination of information about health risks from smoking, restrictions on smoking in public places and in work-places, comprehensive bans on advertising and promotion and increased access to cessation therapies are all effective in reducing tobacco use and its consequences. Despite this evidence, tobacco control policies have been unevenly applied, partially due to political constraints (1). The countries of central Europe bear a disproportionate burden of tobacco-related morbidity and mortality. For example, some of the highest rates of world wide cigarette consumption and smoking prevalence are in Czech Republic, Hungary and Romania (2).

Tobacco, in general, is used as tobacco smoking and smokeless tobacco. Tobacco smoking usually is used in the form of cigarettes, cigars and pipe tobacco (3). Cigarettes form the core of mass production of tobacco product that is smoked globally (4). Over 1.1 billion adults ( $29 \%$ of the adult population) are current smokers of cigarettes worldwide (5). Smokeless tobacco (ST) is normally consumed orally, not smoked. It exists in two major forms: snuff and chewing tobacco. Snuff may be moist or dry. Moist snuff is usually taken as oral snuff. Dry snuff is usually inhaled through the nose and less commonly used. Chewing tobacco is coarser than snuff and exists in three forms: loose-leaf (sold in a soft package or pouch), plug (sold in small block) and twist (dried tobacco leaves that are twisted into strands). Chewing tobacco is usually placed in the oral buccal vestibule, and it is called as "chaw "or "quid" (6). Smokeless tobacco is very commonly used in Scandinavian countries compared to other parts of Europe. Oral use of snuff is very common in Sweden (locally known as suns). Smokeless tobacco products are also consumed in other countries such as India and United States (7).

It has been reported that 700 million children were exposed to environmental tobacco smoke (ETS) or passive smoking. Children are frequently exposed to ETS and it can induce serious diseases like pneumonia, otitis media, asthma, colic, reduction in pulmonary function and high rate of malignancies in children (4). It is very well known that smoking contributes to the development of lung cancer and cardiovascular disease in adults. There is strong evidence that tobacco use has numerous negative effects on oral health, for example, staining of teeth and dental restorations, reduction of the ability to smell and taste, development of oral diseases such as smokers palate, smokers melanosis, coated tongue, and, possibly, oral pre-cancer, oral cancer, oral candidosis, periodontal disease, implant failure and dental caries (8).

The principal objective of this review is to discuss one of the lesser explored area; the influence of tobacco smoking, environmental tobacco smoke or passive smoking and smokeless tobacco on dental caries development. 


\section{SMOKING AND DENTAL CARIES}

Smoking and its relation to dental caries is a subject of many opinions. From early reports in literature and a common belief was that smoking actually helps to reduce dental caries $(9,10$, 11). Schmidt, in 1951, supported this belief when he reported that increase in tobacco smoking was followed by a decrease in caries rate (12). The concentration of thiocyanate, a constituent of tobacco smoke and normal saliva with possible caries-inhibiting effect, was found to be higher in smoker's saliva (13). So, one might predict less dental caries in smokers. On the other hand, the decreased buffering effect and possible lower $\mathrm{pH}$ of smoker's saliva and the higher number of Lactobacilli and Streptococcus mutans may indicate an increased susceptibility to caries (13, 14). In addition, results also showed no significant differences in salivary flow rates between smokers and non-smokers (8). To date, quite a few investigators have discovered a correlation between elevated smoking level and dental caries $(15,16,17,18)$. For example, in 1952, Ludwick and Massler reported that those who smoked more than 15 cigarettes a day had significantly higher number of decayed, missing, and filled teeth (19). In 1971, Ainamo found that increased smoking resulted in significantly higher number of decayed surfaces per dentition and also noted a trend toward more missing surfaces and fewer restored surfaces in subjects with a high consumption of cigarettes (20). In 1990, Zitterbart confirmed association between smoking and the prevalence of dental caries in adult males. Smokers had significantly higher DMFT (Decayed, Missing, and Filled Teeth) score, untreated decayed surfaces, and missing surfaces. He further correlated that more cigarettes consumed per day resulted in more missing tooth surfaces in a smoker's mouth (11). A Swedish study carried out in 1991 shows that smoking, as a habit and an increased number of cigarettes smoked per day, are positively correlated with increased in number of decayed, missing and filled teeth (21). Even though a recent study done on American female population in $2006 \mathrm{did}$ not establish a causative relationship, cigarette smoking was shown to be associated with the prevalence of caries (22).

Studies in this regard have considered multiple variable factors which can contribute directly or indirectly to the increase in the incidence of dental caries in smokers such as age, tobacco habits other than smoking, oral hygiene habits, eating habits, drinking habits, preventive visits to dentist (dental recalls) and overall health standards. Due to these factors, it is difficult to conclude the association between a single positive factor which can cause increase in caries incidence in smokers, therefore, it is not easy to establish the strength of relationship between smoking and dental caries.

Association between smoking and dental caries is well documented in older age groups $(23,24)$. Among middle-age $(15)$ or young adults (25) results are inconsistent. Non-smokers reported more frequent healthy oral health behavior than did daily smokers (26). Studies indicate that smokers not only had bad oral hygiene and less primitive outlook on health, but also had different eating habits, presumably consuming high amount of sugar containing products like soft drinks and snacks $(15,21)$. Daily smoking was associated with increased use of sugar in tea or coffee, and with more frequent alcohol consumption (26). It is also seen that smokers have ineffective brushing habits than non-smokers (20, $27,28)$. The distribution of brushing strokes around the mouth was more uniform in the non-smokers than in the smokers, which may indicate a tendency towards less favorable tooth brushing performance in smokers (29). And current smokers were less likely to report regular preventive visits to dentists and were reluctant to use accessory dental aids such as dental floss. Current smokers also had higher scores on the dental attitudes scale, indicating that a lower value is placed on retaining natural teeth (23).

In natural tobacco, sugar can be present in a level up to $20 \%_{w t}$. In addition, various sugars and sweeteners are added intentionally during tobacco manufacturing process up to $4 \%$ wt or can be up to $13 \%_{\mathrm{wt}}$ of sugars. Sugars used as cigarette additive include glucose, fructose, invert sugar (glucose/fructose mixture) and sucrose. In addition, many tobacco additives contain high amount of sugars. For example, fruit juices, honey, molasses extracts, cones and maple syrup and caramel. The added sugars are usually reported to serve as flavour/casing and humectants. However, sugars also promote tobacco smoking, because they generate acids that neutralize the harsh taste and throat impact of tobacco smoke. Moreover, the sweet taste and the pleasant smell of caramelized sugar flavours are appreciated in particular by starting adolescent smokers (30).

All the above findings can contribute to an increased prevalence of dental caries among smokers. However, a direct etiological relation between smoking and dental caries is still missing. The above-mentioned studies and findings point to the assumption that smoking has some influence on high caries incidence. Further studies, clinical trials and experiments are therefore needed to elucidate the independent effect of smoking as one of the causes of dental caries.

\section{ENVIRONMENTAL TOBACCO SMOKE AND DENTAL CARIES}

It is interesting to know that the data from UK National Diet and Nutrition Survey (1995) suggested maternal smoking as a significant risk factor for predicting caries in preschool children, even when adjusted for social class, nutritional status, and weekly expenditure on confectioneries (31). Work of Aligne and colleagues (2003) based on secondary analysis of the data from Third National Health and Nutrition Survey (1988-1994) has provided strongest evidence yet of an increased risk of dental caries in the deciduous dentition of children who are 4 to 11 years of age and have been exposed to passive smoking or environmental tobacco smoke (ETS) (32). A recent study done in 2004 also confirmed that children residing in regularly smoking homes had significantly higher prevalence of caries compared to nonregular/nonsmoking homes (33).

However, the reason of high predilection of caries in association with ETS, only in children is poorly understood. However, some published data and some hypothesized facts as well as experimental data might support the biological plausibility of causal role of ETS in caries formation in children. It was published that ETS, a common cause of pediatric morbidity and mortality, disproportionately affects children in low socioeconomic status environments. Furthermore, it may be a risk factor for cavities $(32,34)$. Research indicates that the bacteria responsible for caries formation are acquired in infancy from the saliva of mothers (via kissing, etc). Elsewhere, nicotine has been shown to promote 
the growth of cariogenic Streptococcus mutans bacteria in vitro thus, mother who smoke may be more likely than non-smokers to transmit these germs to children $(32,35)$. ETS smoke has immunosuppressive properties and is a known risk factor for infections of the cranial organs (e.g. otitis media); thus it is not surprising that it might be risk factor for caries development as well $(32,36$, 37). In addition ETS is associated with decreased serum vitamin $C$ levels in children and decreased levels of vitamin $C$ are associated with growth of cariogenic bacteria $(32,38,39)$.

It is also possible that ETS may reduce the protective properties of saliva that can operate against caries. Saliva acts as buffering agent when acids are produced. It physically removes debris from the tooth surface, and it has immunological and bacteriostatic properties $(32,40)$. ETS is known to increase inflammation of respiratory tract, producing symptoms of various clinical condition including allergic rhinitis, which frequently cause mouth breathing and thus result in dry mouth (ie. an effective decrease in saliva) $(32,41)$. Thus, ETS could promote dental caries both through a direct effect of nicotine on caries-causing bacterial agents, as well as via other systemic physiological changes in host. Other reason given to that ETS cause caries in children is that colonization with the cariogenic Streptococcus mutans is thought to occur during a window of vulnerability around 1 year of age, and primary teeth are particularly susceptible to caries formation soon after their eruption $(32,42)$. Maternal smoking is also a principal risk factor for pre-maturity, low birth weight, and chronic illness in infancy, while these in turn are all associated with generalized enamel hypoplasia in primary dentition $(32,42,43,44)$. Furthermore, in early childhood, when immune system is generally less mature, the saliva is known to be different from that of adult with respect to IgA concentrations. In addition, salivary flow rate in children is lower $(32,45)$. Young children may thus be particularly vulnerable to harmful effect of ETS on immune system and saliva flow. Hence, it is biologically plausible that passive smoking could cause caries, particularly in early childhood.

Unfortunately, a recent study in 2006 failed to demonstrate a positive association between passive smoking and caries experience in Japanese children (46). And is also some what puzzling that no effect on permanent teeth was observed, as it would be expected that any effect of ETS on the developing dentition would affect both deciduous and permanent teeth in the same way. Similarly, if the main effect of ETS is more related to posterruptive force, then a similar pattern of caries susceptibility in the permanent dentition should be observed. One possible explanation suggests that ETS exposure is more likely to cause dental caries in deciduous teeth rather than permanent teeth is because enamel of deciduous teeth is much thinner compared to permanent teeth, and that enamel defect are associated with caries $(32,47)$.

Authors found all these findings clearly provocative and propose further aggressive studies that could elucidate the causative role of ETS in the dental caries of children and adolescents be carried out.

\section{SMOKELESS TOBACCO AND DENTAL CARIES}

The literature associating smokeless tobacco (ST) use with either increasing or decreasing dental caries incidence is even harder to find than the literature associating tobacco smoking with dental caries. Theories have been postulated based on limited clinical findings, chemical analysis of the content of various ST products, and in vitro effects of ST on the growth of bacteria implicated in caries development.

Evidence linking ST use with increased dental caries prevalence has been reported $(48,49)$. In a case report published by Croft, a 54-year-old patient presented "cervical caries" in the area of tobacco placement and he also had gingivitis and recession in that same tooth $(49,50)$. In contrast, Zitterbart and his colleague did not find any evidence of caries in the area of quid placement in their 36-year-old tobacco chewer $(49,51)$. Another study, which was performed among Swedish children, did not report any prevalence of dental caries among snuff users (52). On the other hand, higher prevalence of caries was observed in snuff dippers than in non-tobacco users among teenagers in Gothenburg. Controlling for cigarette smoking, a dose-response relationship was also shown between caries and the number of years of snuff use (21, 53). A further study was done among baseball players in Phoenix and there were not any differences in dental caries between ST users and non-users even though majority of ST users were snuff dippers rather than chewing tobacco users $(53,54)$.

Studies assessed the total amount of sugar and fluoride percentage in commercially available form of tobaccos. They found that the highest amount of caries promoting factor like sugar and caries inhabiting chemical like fluoride was present in non smoking forms of tobacco like pouch and plug than in smoking form (55). The types of sweeteners and sugars commonly found in ST are fructose, glucose, sucrose, maltose, and isomaltose (56). This addition is presumed to be having a neutralizing effect on the bitter taste of tobacco (30). Large variations in sugar and fluoride levels in tobacco products can exist within form-to-form, store-to-store, brand-to-brand, and state-to-state. This may explain the diverse opinions of dental practitioners and investigators with respect to the concept of tobacco increasing or decreasing incidence of dental caries. Generally, non-smoking form of tobacco are mostly related to promotion of dental caries (55) and present a significant risk factor for developing dental caries (57).

Individuals who chew tobacco appear to have more dental caries than non-users (3). Review of studies conducted from 1988-90 on oral consequences of snuff and chewing tobacco use among professional baseball players in US found that ST use showed a significantly higher prevalence of root caries than did comparable sites in non-smokers (58). Data from the multipurpose health survey (Third National Health and Nutrion Examination Survey) conducted in USA from 1988 to 1994 was used to examine the relationship between chewing tobacco and other forms of tobacco use and decayed or filled coronal or root surface caries. Chewing tobacco users had a slightly higher mean number of decayed and filled coronal surface than individuals using other forms of tobacco. In addition, the mean number of decayed and filled root surface for those who used chewing tobacco was four times higher than for those who did not use tobacco. It is important to note that the decayed or filled surfaces tended to match the side of mouth on which the ST was used, although this did not reach statistical significance. The results showed that the mean number of decayed and filled root surface rose with increasing number of chewing tobacco packages used per week and duration of its use in years (59). A biologically reasonable explanation for an 
association between chewing tobacco use and dental caries is that the high levels of fermentable sugar in ST products can stimulate growth of cariogenic bacteria $(55,59)$.

Users of chewing tobacco have been warned against swallowing it as glucose in chewing tobacco could adversely affect blood glucose level of diabetics (49). The way the chewing tobacco is used creates an environment conducive to dental caries; a wad of tobacco is kept in the oral cavity for 30 minutes on average, and the chewing tobacco is used over an extended period each day $(61,59)$. This assumption is supported by in vitro evidence of stimulated growth of Streptococcus mutans and Streptococcus sanguis in the presence of smokeless tobacco extracts $(35,59)$. It has been also found that extracts from chewing tobacco with high sugar content increased in vitro growth of Lactobacillus casei (59, $61)$, a bacterium implicated in root surface caries $(59,62)$. One in vivo study found that micro-flora associated with root caries comprised a significantly larger proportion of colony-forming units on the root surface of teeth adjacent to the tobacco placement than on the teeth on the contralateral side of the mouth. The study also found significantly high level of collagenase on the side of the mouth where tobacco was placed. It was speculated that increased collagenase activity may interact with specific bacteria to enhance the development of root caries due to the organic nature of cementum $(59,63)$. Another experimental study also found that, aqueous tobacco extracts were used to supplement a basic salts solution (BSS) and a microbial medium. Thin-layer chromatography revealed sucrose in only one of four extracts. Discs saturated with extracts $(0.1-50 \mathrm{mg} / \mathrm{ml})$ failed to inhibit growth of any of the microorganisms. Supplementation $(10 \mathrm{mg} / \mathrm{ml})$ of BSS with the tobaccos lacking sucrose resulted in augmented growth of Streptococcus mutans, Streptococcus salivarius and Streptococcus sanguis, whereas the sucrose-containing brand augmented only Streptococcus sanguis growth. Thus extracts of these smokeless tobaccos would serve as a growth substrate for three species of oral streptococci, which are frequently associated with human dental caries (64).

Another possible contributing mechanism in the development of root-surface caries among snuff/chewing tobacco also results in loss of keratinized gingival and tooth abrasion, yield- ing a periodontal problem at the site where tobacco is held. A significant amount of root surface will be exposed, reflecting the degree of gingival recession and bone loss. The exposed root surface caused by the loss of cementum and some dentin are at increased risk to develop caries (65). ST users are also associated with poor oral hygiene and less sophisticated outlook on heath care (66).

Limited number of epidemiological and experimental results suggests an association between smokeless tobacco usage and dental caries. It seems that smokeless tobacco plays an important role in increased caries activity.

\section{CONCLUSION}

We have discussed in detail different forms of tobacco usage and its direct relationship with the prevalence of dental caries. Among them, oral use of smokeless tobacco shows positive contributing factor for a higher incidence of dental caries predominantly tobacco chewing. One of the main reasons for the association between smokeless tobacco and dental caries is the presence of high amount of various sugars and sweeteners added during the commercial manufacturing of smokeless tobacco products. Unfortunately, published studies are not converging towards one single factor through which tobacco usage can have direct relationship to dental caries. Major masses of published reports are contradicting each other in proving the same. Even though it has been reported that elevated smoking level can be one of the causative factors for dental caries, a direct etiological relation is lacking. It seems at least that smoking is a risk indicator of increased caries activity. But on the other hand it has been proved that smoking associated with old age, bad oral hygiene habits, food habits, limited preventive dental visits and over all health standards, can be associated with high caries incidence. It has been reported that ETS cause dental caries in children but no studies have been reported in adults. Unfortunately, very few studies have been done in this regard. So, findings are not sufficient enough and conclusive that ETS causes dental caries. Hence further studies are required on this subject.

Table 1. Summary of major biological effects of tobacco related to dental caries

\begin{tabular}{|c|c|}
\hline Forms of tobacco use & Biological effects \\
\hline Tobacco smoking & $\begin{array}{l}\text { - } \quad \text { Concentration of thiocynate found to be higher in smoker's saliva may have possible caries inhibiting effect (13). } \\
\text { - Decreased buffering effect and possible lower pH of saliva in smokers may indicate increased susceptibility to caries } \\
(13,14) \text {. } \\
\text { - }\end{array}$ \\
\hline $\begin{array}{l}\text { Environmental tobacco } \\
\text { smoke (ETS) }\end{array}$ & $\begin{array}{l}\text { - } \quad \text { Biological plausibility of causal role of ETS in caries formation in children (32). } \\
\text { - } \quad \text { Immunosuppressive properties of ETS might be a risk factor for dental caries development }(32,36,37) \text {. } \\
\text { ETS may decrease serum vitamin C level, which may be associated with growth of cariogenic bacteria in children (32, } \\
\text { - } \quad \text { ETS may reduce the protective properties of saliva that can operate against caries }(32,40) \text {. }\end{array}$ \\
\hline Smokeless tobacco (ST) & $\begin{array}{l}\text { - } \quad \text { High levels of fermentable sugar and sweeteners in ST can stimulate growth of cariogenic bacteria }(55,56,59) \text {. } \\
\text { - } \quad \text { Extracts from chewing tobacco with high sugar content increased in vitro growth of Lactobacillus casei }(59,61) \text {. } \\
\text { Extracts of ST may serve as a growth substrate for Streptococcus mutans, Streptococcus salivarius and Streptococcus } \\
\text { sanguis (64). }\end{array}$ \\
\hline
\end{tabular}




\section{Acknowledgement}

Supported by grant IGA MZ CR NR 8781-3/2006.

\section{REFERENCES}

1. Jha P, Chaloupka FJ, Corrao M, Jacob B. Reducing the burden of smoking world-wide: effectiveness of interventions and their coverage. Drug Alcohol Rev. 2006 Nov;25(6):597-609.

2. Banoczy J, Squier C. Smoking and disease. Eur J Dent Educ. 2004 Feb;8 Suppl 4:7-10.

3. Winn DM. Tobacco use and oral disease. J Dent Educ. 2001 Apr;65(4):30612.

4. Prokhorov AV, Winickoff JP, Ahluwalia JS, Ossip-Klein D, Tanski S, Lando HA, et al; Tobacco Consortium, American Academy of Pediatrics Center for Child Health Research. Youth tobacco use: a global perspective for child health care clinicians. Pediatrics. 2006 Sep;118(3):e890-903.

5. Anderson P. Global use of alcohol, drugs and tobacco. Drug Alcohol Rev. 2006 Nov;25(6):489-502.

6. Walsh PM, Epstein JB. The oral effects of smokeless tobacco. J Can Dent Assoc. 2000 Jan;66(1):22-5.

7. Furberg H, Lichtenstein P, Pedersen NL, Bulik C, Sullivan PF. Cigarettes and oral snuff use in Sweden: prevalence and transitions. Addiction. 2006 Oct;101(10):1509-15.

8. Reibel J. Tobacco and oral diseases. Update on the evidence, with recommendations. Med Princ Pract. 2003;12 Suppl 1:22-32.

9. Hart AC. Prevention of decay of the teeth. Dent Items Interest. 1899;21(3):153-63.

10. Gibbs MD. Tobacco and dental caries. J Am Coll Dent. 1952;19:365-7.

11. Zitterbart PA, Matranga LF, Christen AG, Park KK, Potter RH. Association between cigarette smoking and the prevalence of dental caries in adult males. Gen Dent. 1990 Nov-Dec;38(6):426-31.

12. Schmidt HJ. Tobacco smoke and the teeth. Stoma (Heidelb). 1951 May;4(2):111-25. (In German.)

13. Johnson NW, Bain CA. Tobacco and oral disease. EU-Working Group on Tobacco and Oral Health. Br Dent J. 2000 Aug 26;189(4):200-6.

14. Kassirer B. Smoking as a risk factor for gingival problems, periodontal problems and caries. Univ Tor Dent J. 1994;7(1):6-10.

15. Axelsson P, Paulander J, Lindhe J. Relationship between smoking and dental status in 35-, 50-, 65-, and 75-year-old individuals. J Clin Periodontol. 1998 Apr;25(4):297-305.

16. Bruno-Ambrosius K, Swanholm G, Twetman S. Eating habits, smoking and toothbrushing in relation to dental caries: a 3-year study in Swedish female teenagers. Int J Paediatr Dent. 2005 May;15(3):190-6.

17. Ide R, Mizoue T, Ueno K, Fujino Y, Yoshimura T. Relationship between cigarette smoking and oral health status. Sangyo Eiseigaku Zasshi. 2002 Jan;44(1):6-11. (In Japanese.)

18. Kelbauskas E, Kelbauskiene S, Nedzelskiene I. The influence of smoking on oral health. Medicina (Kaunas). 2005;41(5):418-26. (In Lithuanian.)

19. Ludwick W, Massler M. Relation of dental caries experience and gingivitis to cigarette smoking in males 17 to 21 years old (at the Great Lakes Naval Training Center). J Dent Res. 1952 Jun;31(3):319-22.

20. Ainamo J. The seeming effect of tobacco consumption on the occurrence of periodontal disease and dental caries. Suom Hammaslaak Toim. 1971;67(2):87-94.

21. Hirsch JM, Livian G, Edward S, Noren JG. Tobacco habits among teenagers in the city of Goteborg, Sweden, and possible association with dental caries. Swed Dent J. 1991;15(3):117-23.

22. Heng CK, Badner VM, Freeman KD. Relationship of cigarette smoking to dental caries in a population of female inmates. J Correct health care. 2006;12(3):164-74.

23. Locker D. Smoking and oral health in older adults. Can J Public Health. 1992 Nov-Dec;83(6):429-32.

24. Jette AM, Feldman HA, Tennstedt SL. Tobacco use: a modifiable risk factor for dental disease among the elderly. Am J Public Health. 1993 Sep;83(9):1271-6.

25. Sgan-Cohen HD, Katz J, Horev T, Dinte A, Eldad A. Trends in caries and associated variables among young Israeli adults over 5 decades. Community Dent Oral Epidemiol. 2000 Jun;28(3):234-40

26. Telivuo M, Kallio P, Berg MA, Korhonen HJ, Murtomaa H. Smoking and oral health: a population survey in Finland. J Public Health Dent. $1995 \cdot 55(3): 133-8$.
27. Kelbauskas E, Kelbauskiene S, Paipaliene P. Smoking and other factors influencing the oral health of Lithuanian Army recruits. Mil Med. 2005 Sep;170(9):791-6.

28. Macgregor ID. Survey of toothbrushing habits in smokers and nonsmokers. Clin Prev Dent. 1985 Nov-Dec;7(6):27-30.

29. Macgregor ID, Rugg-Gunn AJ. Uninstructed toothbrushing behaviour in young adults in relation to cigarette smoking in Newcastle. Community Dent Oral Epidemiol. 1984 Dec;12(6):358-60.

30. Talhout R, Opperhuizen A, van Amsterdam JG. Sugars as tobacco ingredient: effects on mainstream smoke composition. Food Chem Toxicol. 2006 Nov;44(11):1789-98.

31. Williams SA, Kwan SY, Parsons S. Parental smoking practices and caries experience in pre-school children. Caries Res. 2000 Mar-Apr;34(2):11722.

32. Aligne CA, Moss ME, Auinger P, Weitzman M. Association of pediatric dental caries with passive smoking. JAMA. 2003 Mar 12;289(10):1258-64.

33. Shenkin JD, Broffitt B, Levy SM, Warren JJ. The association between environmental tobacco smoke and primary tooth caries. J Public Health Dent. 2004;64(3):184-6.

34. Aligne CA, Stoddard JJ. Tobacco and children. An economic evaluation of the medical effects of parental smoking. Arch Pediatr Adolesc Med. 1997 Jul;151(7):648-53. Erratum in: Arch Pediatr Adolesc Med. 1997 Oct;151(10):988.

35. Lindemeyer RG, Baum RH, Hsu SC, Going RE. In vitro effect of tobacco on the growth of oral cariogenic streptococci. J Am Dent Assoc. 1981 Nov;103(5):719-22.

36. Edwards K, Braun KM, Evans G, Sureka AO, Fan S. Mainstream and sidestream cigarette smoke condensates suppress macrophage responsiveness to interferon gamma. Hum Exp Toxicol. 1999 Apr;18(4):233-40.

37. National Cancer Institute. Health effects of exposure to environmental tobacco smoke: the report of the California Environmental Protection Agency. NIH Publ no. 9-4645. Bethesda: National Institutes of Health; 1999.

38. Strauss RS. Environmental tobacco smoke and serum vitamin $\mathrm{C}$ levels in children. Pediatrics. 2001 Mar;107:540-2.

39. Vaananen MK, Markkanen HA, Tuovinen VJ, Kullaa AM, Karinpaa AM, Luoma H, et al. Dental caries and mutants streptococci in relation to plasma ascorbic acid. Scand J Dent Res. 1994 Apr;102(2):103-8.

40. Mandel ID. The functions of saliva. J Dent Res. 1987 Feb;66 Spec No:623-7

41. Wood RA. Allergic rhinitis. In: Hoekelman RA, Adams HM, Nelson NM, Wilson MH, Weitzman ML, editors. Primary pediatric care. 4th ed. St Louis: Mosby; 2001. p. 1318-20.

42. Seow WK. Biological mechanisms of early childhood caries. Community Dent Oral Epidemiol. 1998;26(1 Suppl):8-27.

43. Charlton A. Children and passive smoking: a review. J Fam Pract. 1994 Mar;38(3):267-77.

44. Nelson E, Jodscheit K, Guo Y. Maternal passive smoking during pregnancy and fetal developmental toxicity. Part 1: gross morphological effects. Hum Exp Toxicol. 1999 Apr; 18(4):252-6.

45. Adair SM. Epidemiology and mechanics of dental disease. In: Pinkham JR, editor. Pediatric dentistry: infancy through adolescence. 3rd ed. Philadelphia: WB Saunders; 1999.

46. Tanaka K, Hanioka T, Miyake Y, Ojima M, Aoyama H. Association of smoking in household and dental caries in Japan. J Public Health Dent. 2006;66(4):279-81.

47. Kidd EAM, Joyston-Bechel S. Essentials of dental caries: the disease and its management. 2nd ed. Oxford: Oxford University Press; 1997.

48. Sitzes L Jr. On chewing tobacco [letter]. ADA news 1977;8:6.

49. Weintraub JA, Burt BA. Periodontal effects and dental caries associated with smokeless tobacco use. Public Health Rep. 1987 Jan-Feb;102(1):30-5.

50. Croft L. Smokeless tobacco. Case report II. Tex Dent J. 1983 Dec;100(12):14-5.

51. Zitterbart PA, Marlin DC, Christen AG. Dental and oral effects observed in a long-term tobacco chewer: case report. J Indiana Dent Assoc. 1983 Jul-Aug;62(4):17-8.

52. Modeer T, Lavstedt S, Ahlund C. Relation between tobacco consumption and oral health in Swedish schoolchildren. Acta Odontol Scand. 1980;38(4):223-7

53. Critchley JA, Unal B. Health effects associated with smokeless tobacco: a systematic review. Thorax. 2003 May;58(5):435-43.

54. Ernster VL, Grady DG, Greene JC, Walsh M, Robertson P, Daniels TE, et al. Smokeless tobacco use and health effect among baseball players. JAMA. 1990 Jul 11;264(2);218-24. 
55. Going RE, Hsu SC, Pollack RL, Haugh LD. Sugar and fluoride content of various forms of tobacco. J Am Dent Assoc. 1980 Jan;100(1):27-33.

56. Hsu SC, Pollack RL, Hsu AF, Going RE. Sugars present in tobacco extracts. J Am Dent Assoc. 1980 Dec;101(6):915-8.

57. Offenbacher S, Weathers DR. Effects of smokeless tobacco on the periodontal, mucosal and caries status of adolescent males. J Oral Pathol. 1985 Feb;14(2):169-81.

58. Robertson PB, Walsh MM, Greene JC. Oral effects of smokeless tobacco use by professional baseball players. Adv Dent Res. 1997 Sep;11(3):30712.

59. Tomar SL, Winn DM. Chewing tobacco use and dental caries among U.S. men. J Am Dent Assoc. 1999 Nov;130(11):1601-10. Erratum in: J Am Dent Assoc. 1999 Dec;130(12):1700.

60. Tomar SL, Winn DM, Swango PA, Giovino GA, Kleinman DV. Oral mucosal smokeless tobacco lesions among adolescents in the United States. J Dent Res. 1997 Jun;76(6):1277-86.
61. Jacks SC, Schroeder KL, Rosen S. In vitro effect of smokeless tobacoo on cariogenic L. casei. J Dent Res. 1989;68 Spec No:390.

62. Nyvad B, Kilian M. Mircroflora associated with experimental root surface caries in humans. Infect Immun. 1990 Jun;58(6):1628-33.

63. Schroeder KL, Rosen S, Ramamurthy NS, Strasyer M. Root caries associalted microflora and collagenase from smokeless tobacco users. J Dent Res. 1989;68 Spec No:390.

64. Falkler WA Jr, Zimmerman ML, Martin SA, Hall ER. The effect of smokeless-tobacco extracts on the growth of oral bacteria of the genus Streptococcus. Arch Oral Biol. 1987;32(3):221-3.

65. Taybos G. Oral changes associated with tobacco use. Am J Med Sci. 2003 Oct;326(4):179-82.

66. Hart GT, Brown DM, Mincer HH. Tobacco use and dental disease. J Tenn Dent Assoc. 1995 Apr;75(2):25-7.

Received April 16, 2007 Received and accepted in revised form June 5, 2007 